\title{
Everolimus: the first approved product for patients with advanced renal cell cancer after sunitinib and/or sorafenib
}

This article was published in the following Dove Press journal:

Biologics:Targets \& Therapy

29 April 2010

Number of times this article has been viewed

\author{
Chris Coppin \\ Medical Oncology, BC Cancer Agency \\ and University of British Columbia, \\ Vancouver, Canada
}

\begin{abstract}
Everolimus (RAD001, Afinitor ${ }^{\mathbb{B}}$ Novartis) is the first oral inhibitor of mTOR (mammalian target of rapamycin) to reach the oncology clinic. Everolimus $10 \mathrm{mg}$ daily achieves complete inhibition of its target at below the maximum tolerable dose for most patients. A phase III randomized placebo-controlled trial has examined the impact of everolimus in patients with clear cell renal cancers and progressive disease on or within 6 months of the VEGFR tyrosine kinase inhibitors sunitinib and/or sorafenib. The primary endpoint of progression-free survival was increased from median 1.9 to 4.9 months (hazard ratio $0.33, P<0.001$ ) and $25 \%$ were still progression-free after 10 months of everolimus therapy. There was a delay in time to decline of performance status and trends to improvement in quality of life, disease-related symptoms, and overall survival despite crossover of the majority of patients assigned to placebo. In 2009, everolimus was approved in the US and Europe as the only validated option for this indication. Toxicities are usually mild to moderate and can be managed with dose reduction or interruption if necessary. Opportunistic infections and non-infectious pneumonitis are seen as a class effect. Management of common practical management issues are discussed. Clinical trials are in progress to examine additional roles for everolimus in renal cancer, alone and in combination with other agents.
\end{abstract}

Keywords: everolimus, drug therapy, advanced renal cancer

\section{Introduction}

Kidney cancer, more specifically renal cell cancer (RCC), is a significant cause of premature death and has been resistant to drug therapy until the past 5 years. There will be a projected 4600 new cases and 1600 deaths from kidney cancer in Canada in $2009,{ }^{1}$ and 8 times that number in the US. ${ }^{2}$ About two-thirds of these events will occur in men, partly related to smoking incidence that increases risk substantially. ${ }^{3}$ There is no proven role for population screening or prevention. An average of 14.2 years of life are lost to each person dying of kidney cancer (based on British Columbia data). ${ }^{4}$

The extent of disease at the initiation of systemic therapy for advanced RCC is a major predictor of outcome, and patients can be divided into three prognostic groups - good, intermediate, or poor risk - using the Memorial Sloan-Kettering criteria ${ }^{5}$ with or without the additional predictive power of the number of involved sites. ${ }^{6}$ The most common presentation of advanced kidney cancer is now during follow-up after nephrectomy: such patients are often asymptomatic and in better general health than in the past with low metastatic burden and less comorbidity. A further substantial fit group of patients will have metastases diagnosed on screening before nephrectomy. Improving survival figures are in part due to lead-time bias from earlier recognition and therapy of metastases with the advent of more options. For example the median survival
Correspondence: Chris Coppin Medical Oncology, Vancouver Island Cancer Centre, 24I0 Lee Road,Victoria, BCV8R 6V5, Canada

Email ccoppin@bccancer.bc.ca 
of the interferon alfa randomized trial arms in two pivotal studies was 9 months in $1999,{ }^{7}$ compared with 20 months in 2008 allowing for crossover to a more active agent. ${ }^{8}$ Patients are therefore often candidates for multiple sequential lines of systemic therapy that are the focus of this review. Smaller cohorts of patients present with symptoms from metastases, paraneoplastic syndromes, or locally advanced tumors in the kidney, and may require a more palliative approach such as radiation as well as attempted systemic therapies.

There have been four eras of systemic therapy for advanced renal cancer: hormone therapy, chemotherapy, immunotherapy, ${ }^{9}$ and currently targeted therapy. ${ }^{10}$ One published randomized controlled trial has used a placebo control demonstrating that the natural history of RCC can sometimes be indolent, with $6.6 \%$ spontaneous partial remissions. ${ }^{11}$ Hormone therapy has been widely used as control therapy ${ }^{7}$ even recently. ${ }^{12}$ RCC is strikingly resistant to chemotherapy despite most new agents being tested. In the 1980s, immunotherapy became the dominant drug therapy, based on occasional durable remissions in highly selected patients treated with high dose interleukin- $2,{ }^{13}$ and small survival gains with the more generally applicable agent interferon alfa. ${ }^{7,14}$ Interferon became the safe and common standard of care for metastatic RCC; ${ }^{5}$ however most patients did not benefit and toxicity was substantial, setting the stage for the present era of targeted drugs. ${ }^{9}$

The first major recent advance was the recognition that renal cell cancer (RCC) includes several diagnostic entities that differ at the molecular level. The most common type of RCC is clear cell (ccRCC), about $75 \%$ of kidney cancers. ${ }^{15}$ Families with the rare von Hippel Lindau syndrome develop vascular tumors including ccRCC, and studies indentified underlying loss of a recessive tumor suppressor gene now known as the VHL gene. Subsequently it was shown that sporadic ccRCC has biallelic deletion, mutation, or methylation of the VHL gene, and this feature has a major role in the pathogenesis of the disease. ${ }^{16}$ Loss of the normal VHL gene product in ccRCC results in constitutional high expression of the hypoxia response gene HIF-1 $\alpha$ (hypoxiainducible factor 1 alpha) and its many downstream products including angiogenic growth factors like vascular endothelial growth factor (VEGF). Recently introduced drugs that target the VEGF pathway include bevacizumab (Avastin ${ }^{\circledR}$; Genentech) with or without interferon alfa, and especially the VEGFR TKIs (VEGF receptor small molecule tyrosine kinase inhibitors) sunitinib (Sutent ${ }^{\circledR}$; Pfizer), sorafenib (Nexavar ${ }^{\circledR}$; Bayer), and others in various stages of development. Of these agents, only sunitinib has resulted in unequivocally improved overall survival for good and intermediate risk patients compared to first-line interferon alfa, ${ }^{17}$ and is now approved and widely used for first-line therapy of advanced ccRCC. Sorafenib is the best documented agent for second-line therapy after interferon alfa. ${ }^{18}$ Therefore there are increasing numbers of good performance status patients in need of further active treatment of metastatic RCC after disease progression on or soon after sunitinib and/or sorafenib. Everolimus (RAD001, Afinitor ${ }^{\circledR}$; Novartis) has emerged as the leader in that setting, and the first to receive approval in the USA (March 2009) and Europe (August 2009) for use after failure of VEGFR TKI therapy. ${ }^{19}$ Poor prognostic risk patients treated with the intravenous mTOR inhibitor temsirolimus (CCI-779, Torisel ${ }^{\circledR}$ Wyeth) have improved overall survival, ${ }^{20}$ but represent a more palliative clinical situation than good-intermediate risk patients suitable for multiple lines of therapy.

\section{Discovery and development of rapamycin and rapalogs}

Rapamycin (sirolimus) is a macrolide antibiotic named for the remote Pacific island of Rapa Nui (formerly Easter Island), the origin of a soil sample obtained in 1965 (Figure 1) which yielded a new streptomycete, Streptomyces hygroscopicus, from which rapamycin was later derived at Ayerst Research Labs in Montreal. ${ }^{21}$ This discovery deserves major recognition because extended investigations of rapamycin and its derivatives successively demonstrated a unique combination of antifungal, immunosuppressive, ${ }^{22}$ antineoplastic, ${ }^{23}$ and even anti-aging properties. ${ }^{24}$ In 1999,

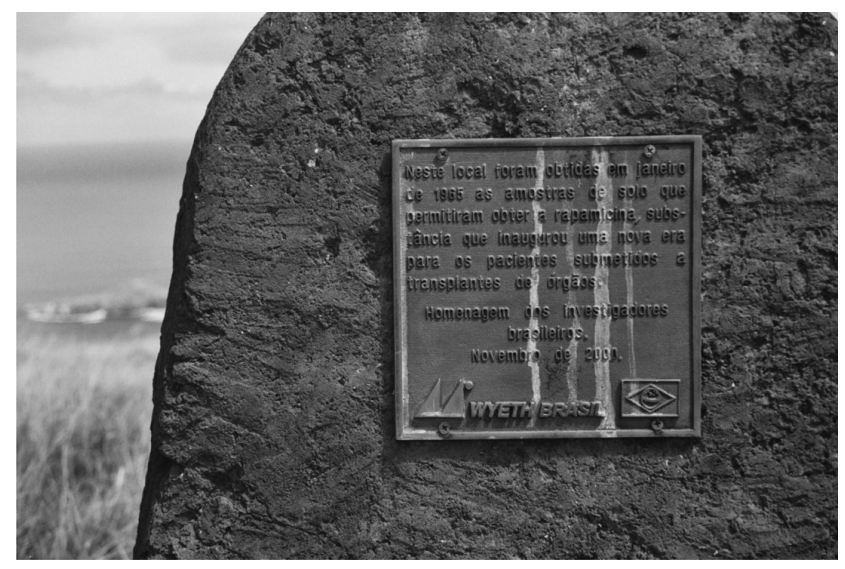

Figure I A plaque commemorating the discovery of rapamycin (sirolimus) on Rapa Nui (Easter Island), near Rano Kau. The plaque is written in Brazilian Portuguese, and reads: In this location were obtained, in January 1965, soil samples that led to the discovery of rapamycin, a substance that inaugurated a new era for organ transplant patients. An homage from the Brazilian investigators, November 2000. Photo credit: Anypodetos, Wikipedia Commons. 
rapamycin was approved in the USA for immunosuppression after organ transplantation and marketed as Rapamune ${ }^{\circledR}$ (Wyeth-Ayerst). Its target is a highly conserved kinase known in mammals as mTOR (mammalian target of rapamycin). Rapamycin has no other target so the inhibition of mTOR is one of the most specific targeted drug actions known.

The original compound rapamycin was too insoluble and unstable for parenteral use as an antineoplastic agent. ${ }^{25}$ Subsequently rapamycin ester analogs have been developed, known as rapamycins, ${ }^{25}$ or rapalogs ${ }^{26}$ Current rapalogs include temsirolimus, everolimus (RAD001, Afinitor ${ }^{\circledR}$ ), and agents still in development such as ridaforolimus (deforolimus, AP23473 Ariad $^{\circledR}$; Ariad Pharmaceuticals). These rapalogs have similar and highly selective action discussed below such that at least some overlap of clinical efficacy, toxicity, and predictors of benefit might be expected.

\section{Mechanism of action of rapalogs}

mTOR has a role in cell growth, proliferation, cell survival, and angiogenesis. Unravelling mTOR function is still incomplete but much progress has been made and a number of excellent reviews are available. ${ }^{23,25-30}$ Originally identified from rapamycin-resistant yeast strains, TOR and its homologues are highly conserved in evolution, and centrally located in molecular pathways involved in cell proliferative responses to external factors including insulin-like growth factors and availability of oxygen and nutrients. mTOR is a large single chain polypeptide with 2549 amino acids and at least 5 binding domains (Figure 2).

mTOR forms two different multi-protein complexes called mTORC1 and mTORC2. mTORC1 is formed with raptor (regulatory protein of $\mathrm{mTOR}$ ) and $\mathrm{mLST} 8$, and upon activation via the upstream PI3K-Akt pathway, has Ser/Thr kinase activity for its main downstream targets S6K1 (ribosomal p70S6 kinase 1), and 4E-BP1 (4E binding protein 1) resulting in disinhibition of the eukaryotic initiation factor 4E (eIF4E) and translation of multiple cell cycle regulating proteins (Figure 3 ). Recently an additional component of mTORC1, PRAS40 (proline rich Akt substrate $40 \mathrm{kDa}$ ), has been described that may allow Akt to directly inhibit TORC1 in energy-deprived conditions. ${ }^{23}$ mTORC1, but not mTORC2, is directly inhibited by rapamycin complexed to a cytophilin FKBP12 (originally identified as the binding protein for the immunosuppressive agent tacrolimus, FK506). Rapamycin binds with high affinity ( $\mathrm{Kd} \sim 0.3 \mathrm{nM})$ and specificity by binding into a hydrophobic cleft between mTOR and FKBP12. ${ }^{31}$

mTORC1 is located on the PI3K-Akt-mTOR-p70S6K pathway, upregulated in many malignancies, that increases transcription of protein RNAs including HIF-1 (hypoxia inducible factor 1). HIF-1 lies at the crossroads for agents that target the mTOR pathway and those that target the VEGF pathway discussed earlier, thereby providing the basis for consecutive or concurrent use of agents that target the two

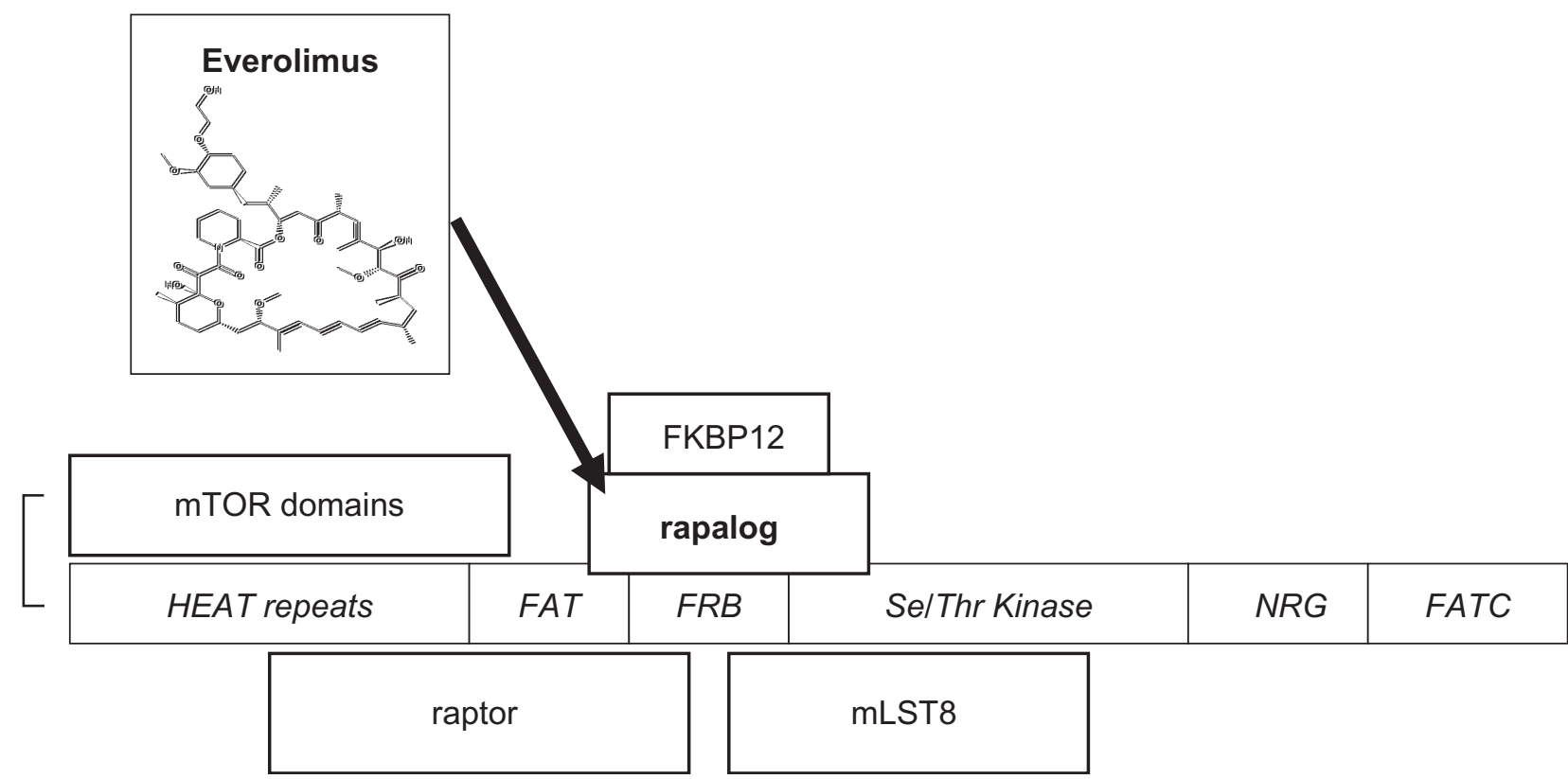

Figure $2 \mathrm{mTORCI}$, mammalian target of rapamycin complex I, consists of mTOR, raptor (regulatory protein of mTOR), and mLST8 (mammalian lethal with SEC I3). An additional component, PRAS40, has been omitted (see text). mTOR domains ${ }^{27}$ are shown in italics. The serine/threonine kinase catalytic activity is inhibited by the binding to FRB (FKBPI2-rapamycin binding protein) of the rapalog-FKBPI2 complex (rapamycin analogs complexed to the cytophilin FK-506 binding protein I2 kD). 


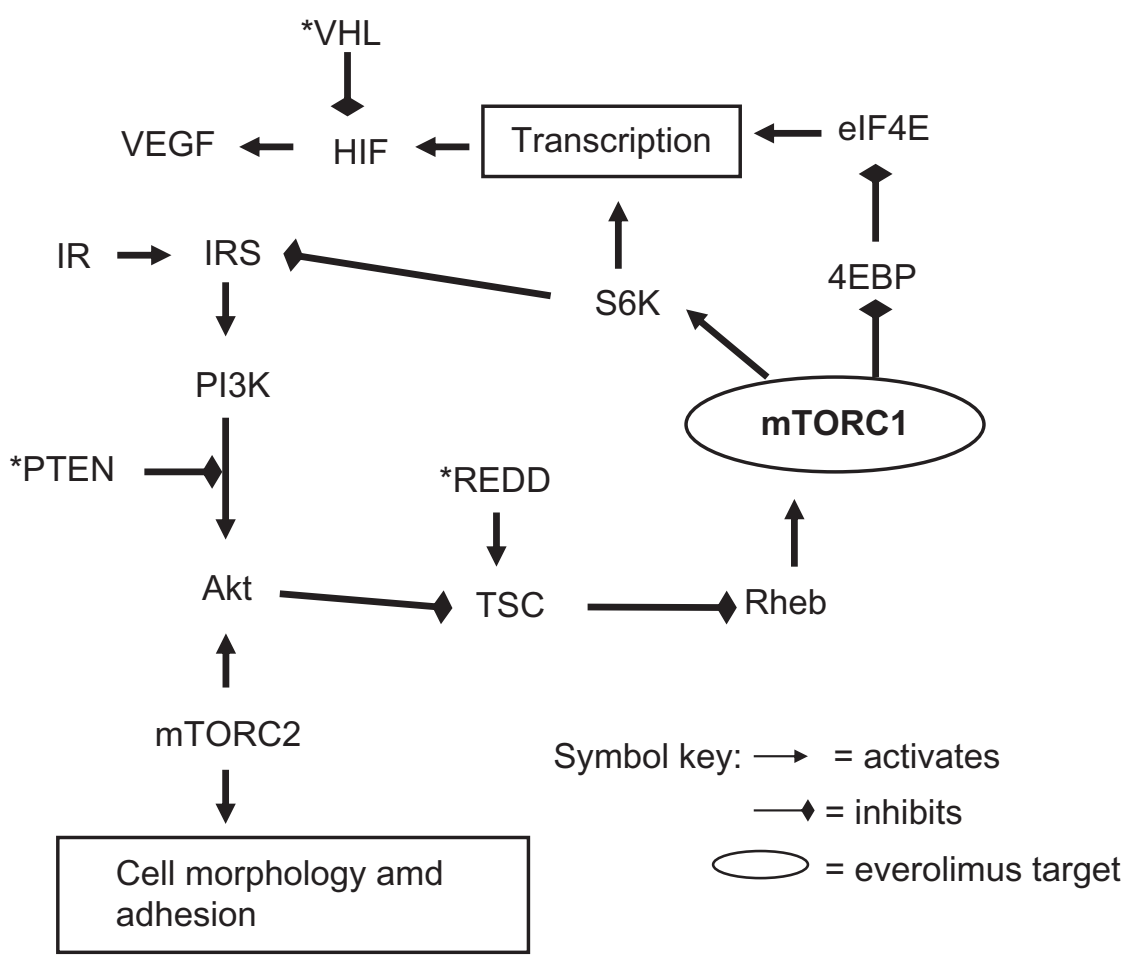

Figure 3 Major mTOR pathways.

Notes: $\mathrm{mTORCI}=\mathrm{mTOR}$ complex I, the major site of inhibition for everolimus, but also results in disruption of negative feedback loop via S6K; $\mathrm{mTORC2}$ inhibition occurs in a minority of cell lines; $*$ = tumor suppressor gene, may be inactivated in RCC; $*$ PTEN = phosphatase and tensin homologue; *VHL =Von Hippel Lindau gene product; $*$ REDD = regulated in development and DNA damage; IR = insulin receptor; IRS = insulin receptor substrate; PI3K = phosphoinositol 3 kinase; TSC = tuberous sclerosis complex; Rheb = Ras homologue enriched in brain; $\mathrm{S6K}=$ ribosomal p70S6 kinase; $4 \mathrm{EBP}=4 \mathrm{E}$ binding protein; elF4E = eukaryotic initiation factor 4E; HIF = hypoxia inducible factor; VEGF = vascular endothelial growth factor.

pathways. It should however be noted that the site of action for VEGF targeted agents is thought to be vascular endothelial cells, whereas mTOR inhibitors act directly on tumor cells, as well as support tissues such as vascular endothelium where there are differences from VEGFR inhibitors. ${ }^{32}$ The combined pathway actions of everolimus provide a rationale for radiosensitization especially observed against vascular endothelium..$^{33}$ Strategies for overcoming resistance may be novel for targeted agents and different for the VEGF and mTOR pathways. ${ }^{34}$

The role of a second complex of mTOR, mTORC2, is becoming clearer and requires revision of the simplistic cascade referred to previously. Inhibition of mTOR disrupts S6K negative feedback on the insulin receptor substrate (IRS) precursor of the Akt pathway resulting in undesirable upregulation and a potential mechanism of resistance. ${ }^{35}$ However in a minority of cell lines, prolonged rapamycin exposure also inhibits mTORC2 that is a key activator of Akt and therefore could mitigate or even block the Akt pathway. ${ }^{28,29}$ The mechanism of rapamycin inhibition of mTORC2 is not fully elucidated but could be by intracellular scavenging of mTOR. Another reason to block mTORC2 is that it appears to control the expression of HIF- $2 \alpha$ that may be more important than HIF-1 $\alpha$ in RCC. ${ }^{36}$ The complex pathway feedback loops are challenging for disease control but also provide numerous opportunities for the combination of everolimus with agents that block other targets, ${ }^{23}$ but whether these combinations will prove to have a higher therapeutic index than their consecutive use remains to be seen.

\section{Clinical pharmacology}

The approach to determining the standard dose of a chemotherapy agent in phase I trial is escalation to the maximum tolerated dose (MTD). However, targeted agents may fully block their target(s) below the MTD and this dose may be directly assessed especially where there is a single target as with mTOR inhibitors. ${ }^{37}$ Such an approach was used in the clinical development of temsirolimus and subsequently with everolimus. The dose-dependant antitumor efficacy of everolimus was shown in a rat pancreatic tumor model to correlate with prolonged inactivation of ribosomal protein S6 kinase $1 .^{38}$ This relationship was examined in detail in phase I human studies with similar effects also seen for the other mTOR downstream effector eukaryotic initiation factor $\mathrm{p} 4 \mathrm{E}-\mathrm{BP} 1 .^{39,40}$ Modelling suggested that a daily schedule would exert a greater effect 
than weekly administration. ${ }^{41}$ Everolimus $10 \mathrm{mg}$ by mouth daily was recommended for phase II studies. ${ }^{42}$

At least five metabolites of everolimus are known, all with low mTOR inhibitory effect. ${ }^{43}$ Unlike temsirolimus, everolimus is not a prodrug of rapamycin. The majority of metabolite excretion is hepatic - biliary - fecal. The peak concentration is reduced by a high fat diet, but the AUC is not; the AUC is proportional to dose. The terminal half-life is approximately 30 hours. $^{44}$

\section{Efficacy of everolimus: phase II}

A phase II study of everolimus $10 \mathrm{mg}$ daily for ccRCC has been completed and fully published. ${ }^{45}$ Forty-one patients were enrolled and were generally good performance status and minimally treated: $17 \%$ had no prior systemic therapy, $62 \%$ had one prior immunotherapy, and $22 \%$ had a VEGF inhibitor or other therapy. 37 were assessable for efficacy, with $14 \%$ objective partial remissions lasting 8 to 37 months and another $57 \%$ with stable disease for more than 6 months (the majority with at least minor tumor shrinkage). The safety analysis observed grade 1-2 anorexia, nausea, diarrhea, rash, and stomatitis in $>10 \%$ of treated patients, grade 1-3 pneumonitis in 49\%, and a variety of laboratory changes. However only $13 / 39$ patients required a dose reduction to $5 \mathrm{mg}$, and no patient withdrew because of drug toxicity. These findings were confirmed in an additional cohort of patients previously treated with sunitinib or sorafenib ${ }^{46}$ paving the way to the subsequent phase III study.

\section{Second-line phase III study: RECORD-I; NCT004 I 0 I 24 (clinicaltrials.gov) RECORD-I (REnal Cell cancer treatment with Oral RAD00I given Daily)}

A pivotal trial of second-line everolimus for advanced clear cell RCC has been fully reported. ${ }^{47,48}$ All patients had progressive disease on $(75 \%)$ or within 6 months $(25 \%)$ after prior treatment with sunitinib, sorafenib, or both agents. Patient eligibility also required measurable disease, as well as adequate organ function and Karnofsky performance status (minimum KPS $70 \%$, capable of self-care). The investigators used exemplary design and methodology, with central randomization, placebo control, independent blind radiologic review, and intent-to-treat analysis. It was powered to detect a $50 \%$ improvement in the primary endpoint of progression-free survival (PFS) allowing for two interim analyses. Patients were stratified by risk category, ${ }^{49}$ and by number of VEGFR TKIs (1 vs 2). All 410 enrolled patients received best supportive care; additionally two thirds of patients were randomly assigned to receive everolimus and one third received identically appearing placebo tablets. The patients, investigators, and independent assessment reviewers were all unaware of the random assignment. Everolimus $10 \mathrm{mg}$ was taken daily by mouth unless protocol-specified adverse events (AEs) required a delay and/or dose reduction to $5 \mathrm{mg}$ daily. Over three-quarters of enrolled patients were KPS $90 \%$ to $100 \%$ despite being heavily pretreated - over half had received immunotherapy, chemotherapy, or radiation in addition to sunitinib and/or sorafenib. The trial was closed early after the second interim analysis (first efficacy analysis) showed that a pre-specified degree of benefit had been surpassed and the criterion for a positive study met. The risk for disease progression at study closure on the everolimus arm was reduced by $70 \%$ compared to placebo (Figure 4 ) with similar reduction on more mature analysis (hazard ratio [HR] $0.33,95 \%$ confidence interval [CI] 0.25 to 0.43 , $P<0.001) .{ }^{48}$ All pre-specified and exploratory subgroups appeared to show improvement in the primary outcome of delayed progression resulting from disease stabilization and minor tumor shrinkage: $67 \%$ of everolimus vs $32 \%$ placebotreated patients had stable disease for at least 8 weeks. Updated median PFS was 4.9 vs 1.9 months and, more importantly, the probability of remaining progression-free for at least 10 months was $25 \%$ on everolimus vs $<2 \%$ on placebo. ${ }^{48}$ However remissions as conventionally defined by RECIST criteria ${ }^{50}$ occurred in only $2 \%$ of patients on the active treatment arm, and overall survival was similar for patients receiving everolimus or placebo. There was no difference in the time to deterioration of global quality of life (QOL) in the initial report, ${ }^{47}$ but subsequent analyses of performance status and disease-related symptoms did suggest a benefit. ${ }^{48}$ The time to a decline in performance status was longer on everolimus than placebo (5.8 vs 3.8 months, HR $0.66, P=0.004)$. A summary of efficacy measures from the RECORD-1 trial is presented in Table 1.

Therefore although a robust biological effect was clearly demonstrated, the clinical utility of this effect is less obvious and interpretation is required. For example, it is possible that there were beneficial effects on QOL resulting from stability and minor remissions that were offset by adverse effects of everolimus, a balance that might be quite sensitive to the details of toxicity management. PFS benefit may be a predictor of overall survival impact for this disease, ${ }^{51,52}$ and a beneficial impact on survival might be obscured by the protocol requirement to permit crossover of placebo-treated 


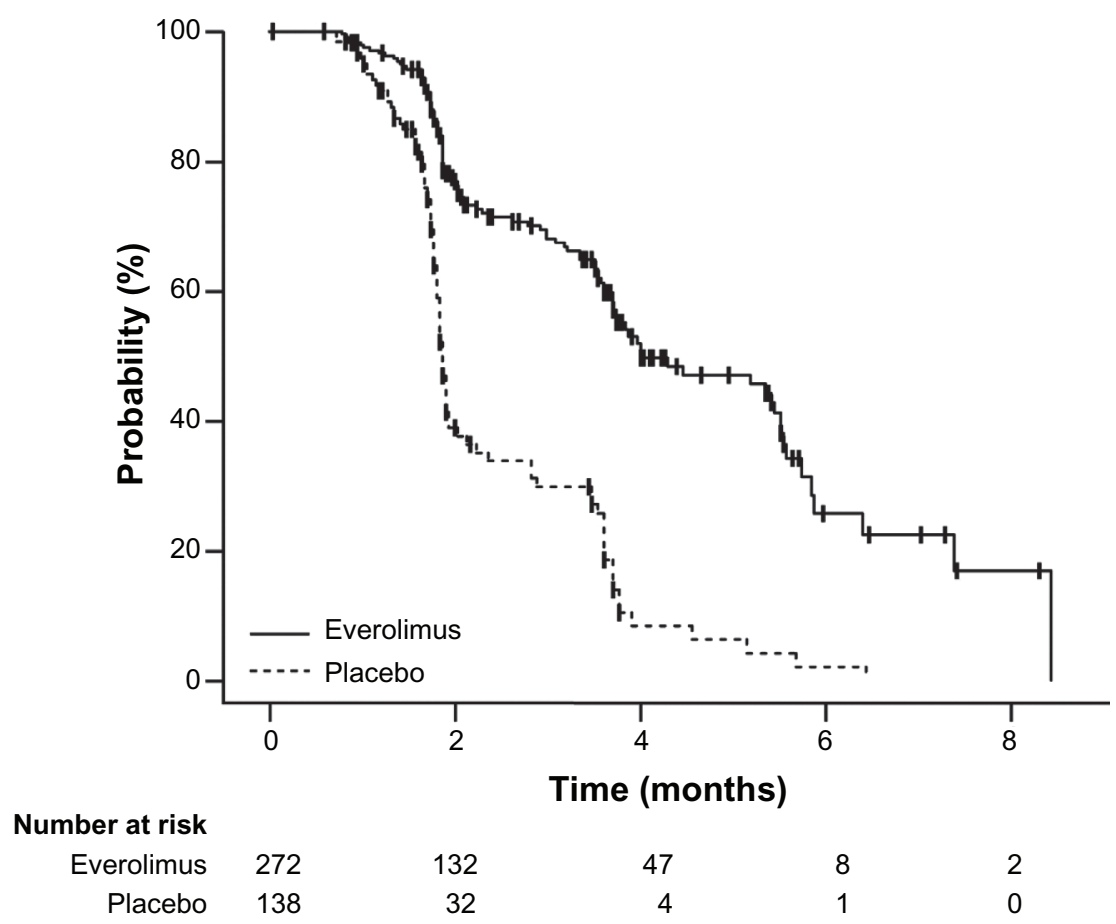

Figure 4 Kaplan-Meier estimates of progression-free survival. Reprinted from The Lancet. 372:449-456. Motzer RJ, Escudier B, Oudard S, et al. Efficacy of everolimus in advanced renal cell carcinoma: a double-blind, randomised, placebo-controlled phase III trial. Copyright (C) 2008, with permission from Elsevier.

patients to receive everolimus after investigator-assessed disease progression, justified by ethical and recruitment considerations; ${ }^{47} 112 / 139(81 \%)$ patients initially assigned to placebo did cross to everolimus and enjoyed a median PFS of 5.1 months, ie, very similar duration to those initially assigned to the everolimus arm. In the absence of standardized ways to examine such possibilities, further analyses by post-hoc crossover censoring techniques must be regarded as hypothesis generating but are consistent with an improvement in overall survival (Table 1). ${ }^{53,54}$

\section{Safety and tolerability of everolimus}

Everolimus has turned out to be relatively safe and well tolerated, considering that mTOR blockade might cause disruption of diverse molecular pathways or serious consequences of immunosuppression. In the pivotal phase III study, ${ }^{47}$ safety was evaluated every 2 weeks for 6 weeks and then monthly, using the US National Cancer Institute Criteria v3.0. ${ }^{55}$ Due to adverse events, $39 \%$ of patients required a dose reduction from everolimus $10 \mathrm{mg}$ to $5 \mathrm{mg}$ by mouth daily, with or without temporary interruption of therapy, compared to $15 \%$ on placebo; $13 \%$ discontinued active treatment because of toxicity compared with $2 \%$ on placebo, usually because of lung disorder or fatigue..$^{47,48}$ The subjective toxicities that were seen at least $10 \%$ more often in patients assigned to everolimus compared to placebo were stomatitis or mucosal inflammation, rash, asthenia, diarrhea, and nausea, mostly grade 1 or 2 . Anemia and fatigue were common in both study arms. The following events occurred to grade 3 or 4 significantly more often

Table I Efficacy measures from RECORD-I trial

\begin{tabular}{|c|c|c|c|c|}
\hline & Everolimus & Placebo & HR & $P$ \\
\hline Progression-free survival| ${ }^{47}$ & 4.9 months & 1.9 months & 0.33 & $<0.001$ \\
\hline Overall survival (OS) ${ }^{48}$ & 14.8 months & 14.4 months & 0.87 & 0.177 \\
\hline${ }^{\mathrm{a}} \mathrm{OS}(\text { method I) })^{53}$ & & & 0.55 & 0.039 \\
\hline${ }^{\mathrm{a}} \mathrm{OS}(\operatorname{method} 2)^{54}$ & I4.8 months & 10.0 months & 0.53 & not statec \\
\hline Time to PS decline ${ }^{48}$ & 5.8 months & 3.8 months & 0.66 & 0.004 \\
\hline KFSI-DRS score ${ }^{48}$ & 4.8 & 3.8 & 0.75 & 0.053 \\
\hline
\end{tabular}

aCorrected for crossover after disease progression on placebo to everolimus.

Abbreviations: KFSI-DRS score, FACT-Kidney Symptom Index - Disease Related Symptoms; OS, overall survival; PS, performance status. 
Table 2 Serious adverse events in RECORD-I trial $\left.\right|^{47,48}$

\begin{tabular}{lll}
\hline & Everolimus & Placebo \\
\hline Treatment-related death & $1 \%$ & 0 \\
Discontinued for AE & $13 \%$ & $2 \%$ \\
Dose reduction for AE & $39 \%$ & $15 \%$ \\
Clinical pneumonitis & $14 \%$ & 0 \\
Infections & $13 \%$ & $2 \%$ \\
Stomatitis gr 3-4 & $3 \%$ & 0 \\
Lymphopenia gr 3-4 & $15 \%$ & $5 \%$ \\
Hyperglycemia gr 3-4 & $12 \%$ & $1 \%$ \\
High cholesterol gr 3-4 & $3 \%$ & 0 \\
\hline
\end{tabular}

Abbreviations: $A E$, adverse event; gr, grade ${ }^{55}$

in patients receiving everolimus than placebo: stomatitis, infections, pneumonitis, elevated cholesterol, hyperglycemia, lymphopenia, and hypophosphatemia. Four deaths were attributed to everolimus, one each due to pneumonitis, sepsis, candidiasis, and aspergillosis (Table 2).

A serious class toxicity for rapalogs including everolimus is drug-induced (non-infectious) pneumonitis, ${ }^{56}$ and this may be substantially more common than clinically apparent. For example, a blinded retrospective review of a phase III trial of temsirolimus found that $29 \%$ of patients had radiologic pneumonitis, compared to $9 \%$ clinical pneumonitis with dyspnea or cough and only $1 \%$ discontinued therapy. ${ }^{57}$ Likewise, a single institution subset of the RECORD-1 pivotal study of everolimus observed CT radiologic changes in $46 \%$ but only $7 \%$ clinical drug-induced pneumonitis. ${ }^{58}$ Only grade 3 or clinical pneumonitis requires drug interruption or discontinuation, others may be treated symptomatically and monitored for deterioration or resolution; grade 4 life-threatening pneumonitis was not seen. The average time to development of pneumonitis was 4 months and half were treated with steroids. ${ }^{48}$ A more detailed analysis and recommendations for pneumonitis management arising from this study is pending. ${ }^{47}$

\section{Expanded access experience of everolimus}

Following presentation of the early RECORD-1 study results, ${ }^{59}$ in July 2008 an expanded access program that made everolimus available to patients following therapy with sunitinib or sorafenib had enrolled 342 patients in 22 countries as of April 2009, ${ }^{60}$ and is ongoing in some locations pending regulatory approval. ${ }^{61}$ Eligibility permitted non-measurable disease. The safety profile is similar to the phase III study with no new toxicities recognized. Seventeen percent discontinued due to AE, similar to the phase III experience. However, of the first 168 patients for whom data are available, $71 \%$ experienced at least one grade 3 or 4 toxicity, suggesting that close monitoring and patient education are required to more clearly define the indications for dose reduction or interruption for evolving toxicity.

The question arises as to the use of everolimus following disease progression with new VEGFR tyrosine kinase inhibitors as these become available for study. The most recent additions to this drug family are axitinib (AG13736, Pfizer) and pazopanib (GW786034, GlaxoSmithKline), oral multikinase inhibitors with demonstrated activity in phase II studies and now in phase III trials. In phase II, pazopanib achieved a $35 \%$ objective response rate in patients who had not received prior VEGFR TKI therapy. ${ }^{62}$ Axitinib achieved a response rate of $23 \%$ in patients who had all received prior sorafenib. ${ }^{63}$ Such patients would appear to be eligible for inclusion in the expanded access study of everolimus, ${ }^{61}$ and the differential efficacy of everolimus after different VEGFR TKI sequences may become available in due course. In the meantime it is reasonable to use everolimus in this setting based on generally similar experience after sunitinib or sorafenib.

Although we do not yet have patient satisfaction data, it is likely that this treatment will be well received since it is very convenient as a daily oral pill, has proven efficacy in stabilizing the disease temporarily in the majority of patients, and is the only proven effective option after failure of VEGR TKIs. Significant toxicity is seen but, in most patients, is readily manageable with symptomatic care and dose modification or temporary interruption.

\section{Practical management of safety issues}

The integration of everolimus into clinical practice is at a preliminary stage. It appears that the safety profile of oral everolimus is similar to its analog temsirolimus, available since 2007 as a weekly intravenous treatment and for which practical management is well established. ${ }^{64-66}$ The principles are: safety monitoring, early detection of toxicities or disease progression, and action appropriate to a palliative therapy. Serious toxicity is to be minimized by early treatment interruption and restart at a reduced dose of everolimus $5 \mathrm{mg} /$ day if tolerated.

\section{Patient selection}

Approved patient selection is for tyrosine kinase refractory disease (progression on or immediately after), ambulatory performance status, adequate bone marrow and hepatic function, and clear cell predominant histology. 
Table 3 Practical recommendations for everolimus therapy ${ }^{44}$

\section{Pretreatment checklist}

I. Pretreatment suitability (see text 'Patient-selection').

2. Medication list for CYP450 3A4 inhibitors or inducers (strong inhibitors should not be co-administered). ${ }^{66}$

3. Afinitor ${ }^{\circledast}$ counseling information eg, common adverse events, avoid live vaccines and grapefruit juice

4. Provide patient with reporting instructions, eg, fever, respiratory symptoms

5. Record baseline tumor/symptom evaluation, repeat every 8 weeks

6. Lab at baseline and every 4 weeks (or more often if risk factors such as diabetes are present)

$\mathrm{Lab}=\mathrm{CBC}$ and differential, phosphorus, LFT, creatinine, fasting glucose, cholesterol, triglycerides

7. CXR at baseline and every 8 weeks or if cough/dyspnea develop

8. CT chest if lung disease or lung metastases present: at baseline and as needed for re-evaluation

Duration until disease-progression, unacceptable toxicity despite dose reduction, or patient refusal

\section{Dosage modification}

Note: dose is not adjusted for body size (did not reduce interpatient variation for temsirolimus). ${ }^{67}$

\section{Common situations}

100\%: everolimus $10 \mathrm{mg}$ by mouth daily taken consistently at same time and with or without food

$50 \%: 5 \mathrm{mg}$ daily for grade 3-4 toxicities on full dose, after interruption until grade 2 or better

Special situations

On CYP450 3A4 inducer: cautious dose escalation if no grade 2 toxicity after 4 weeks at $10 \mathrm{mg}$

On CYP450 3A4 strong inhibitor: start at $5 \mathrm{mg}$ daily, increase cautiously after 4 weeks if no grade $2 \mathrm{AE}$

Persistent or unacceptable grade 2 toxicities at $10 \mathrm{mg}$ dose: $10 \mathrm{mg}$ alternating with $5 \mathrm{mg}$

Moderate hepatic impairment (Child-Pugh class B): $5 \mathrm{mg}$ daily

Renal impairment: no modification required

\section{Management of specific problems}

Neutropenic infections - as for chemotherapy-related febrile neutropenia

Lymphopenic infections - consider possible opportunistic infections such as Candida or Aspergillus

Non-infectious pneumonitis (by exclusion - no clinical or other evidence of infection)

- grade I-2, continue everolimus but monitor weekly until stable/improving

- grade 3, hold therapy until improved; consider corticosteroid eg, prednisone 25-50 mg with rapid taper before resuming everolimus at lower dose

Hyperglycemia - home glucometer, diet modification/oral agents or insulin as required, maintain dose

Hypertriglyceridemia - diet modification

Hypercholesterolemia - diet modification; prevastatin if necessary (other statins are CYP450 substrates) ${ }^{66}$

Hypophosphatemia - oral phosphate replacement

Stomatitis, rash, diarrhea - symptomatic management

Diabetics: high risk of hyperglycemia grade $2+$ (based on temsirolimus data) ${ }^{68}$

Abbreviations: AE, adverse events; $\mathrm{CBC}$, complete blood count and differential; LFT, liver function tests; CXR, chest X-ray; CT, computerized tomography.

Where permitted, off-label use in non-clear cell RCC may be considered since temsirolimus has some evidence to support its use in that context. ${ }^{69}$ Everolimus is in phase II for patients with papillary renal cancers, ${ }^{70,71}$ and prior to nephrectomy for patients with metastases at diagnosis. ${ }^{72}$

\section{Prediction of benefit of $\mathrm{mTOR}$ inhibitors}

Much needed for targeted agents in general are biomarkers to predict patients who are more likely or very unlikely to benefit. A substantial study of 375 patients investigated the prognostic significance of mTOR pathway components in tumors obtained at nephrectomy, and observed adverse prognostic impact on disease-specific survival of pS6K,
PTEN and Akt independent of stage. ${ }^{73}$ A small study further suggested that $\mathrm{pS6K}$ and possibly Akt were predictors of response to temsirolimus for advanced RCC. ${ }^{67,74}$ However an extension of the study ${ }^{20}$ of temsirolimus for poor prognosis advanced RCC did not find a correlation between PTEN and HIF- $1 \alpha$ with outcome. ${ }^{75}$ Work on biomarkers to predict benefit of everolimus is underway. ${ }^{76}$ Once treatment is initiated, it may be possible to assess pharmacokinetic effects on glucose metabolism in as little as a week by PET scanning. ${ }^{77}$

\section{Ongoing clinical research}

Everolimus has an established place as the preferred single agent for second-line treatment of ccRCC after sunitinib and/or sorafenib. Research is actively examining additional 
scenarios for its use. Many combinations of everolimus with other classes of targeted drugs or chemotherapy are being tested in phase I/II trials. The relevant combinations for ccRCC combine everolimus with another agent that targets the same PI3K/Akt/mTOR pathway at another level (vertical blockade), or a different pathway (horizontal blockade). ${ }^{78}$ Vertical blockade with everolimus and imatinib was toxic, gave PFS similar to everolimus alone, and was not recommended for further development. ${ }^{79}$ Horizontal blockade combining everolimus with a VEGF pathway inhibitor is proceeding actively eg, sunitinib, ${ }^{80}$ sorafenib,${ }^{81}$ or bevacizumab. Of these, the everolimus - bevacizumab combination is the only one where both drugs are tolerated at full dose, ${ }^{82}$ has promising activity, ${ }^{83}$ and has now reached randomized phase II testing compared to the established IFN-bevacizumab regimen in the first-line setting (RECORD-2 study). ${ }^{84}$ Agents that block mTOR complex 2 or the S6K feedback loop (Figure 3) would be of special interest. ${ }^{26}$

Now that multiple oral targeted agents are available and adequately well tolerated for chronic use, trials are starting to examine whether there might be a preferred sequence eg, for inhibition of the mTOR and VEGF pathways. The phase III RECORD-3 study ${ }^{85}$ will randomize patients to everolimus or sunitinib first-line, and cross-over to the other agent at disease progression.

\section{Conclusions}

Consequent to a large well performed phase III trial, everolimus has become the standard second-line agent after the approved first-line drugs sunitinib and/or sorafenib for patients with advanced clear cell renal cancer. The majority of patients with advanced disease are now diagnosed early at presentation or on surveillance after nephrectomy and remain in good performance status for an extended time and so are eligible for everolimus. Everolimus has been recently approved by the FDA in the USA, and by European Medicines Agency in Europe. Guidelines in developed countries for the treatment of RCC are reasonably concordant, ${ }^{86}$ and now include everolimus as the preferred treatment for VEGFR inhibitor resistant disease in the USA, ${ }^{87}$ Europe, ${ }^{88}$ and Canada. ${ }^{89}$ Future randomized trials in the second-line setting after VEGF pathway inhibitors will need to use everolimus as comparator in the control arm. The benefits of second-line everolimus are modest with temporary stablization the most common advantage over placebo. Everolimus drug combinations and/or use earlier in the disease may confer greater benefits. The impact on overall survival has become difficult to demonstrate because of crossover of patients to the alternate arm. Validated and agreed statistical methods are needed and appear feasible for the use of censoring techniques to determine survival benefit in a crossover setting. ${ }^{53,54}$

\section{Disclosure}

The author declares no conflicts of interest.

\section{References}

1. Canadian Cancer Society's Steering Committee: Canadian Cancer Statistics 2009. Toronto: Canadian Cancer Society, 2009. www.cancer. ca/statistics. Accessed Nov 30, 2009.

2. Jemal A, Siegal R, Ward E, Hao Y, Xu J, Thun MJ. Cancer statistics, 2009. Ca Cancer J Clin. 2008;59:225-249.

3. Moore LE, Wilson RT. Lifestyle factors, exposures, genetic susceptibility, and renal cell cancer risk: a review. Cancer Invest. 2005;23:240-255.

4. British Columbia Cancer Registry. Potential years of life lost. BC Cancer Agency, Vancouver BC, Canada. www.bccancer.bc.ca/HPI/ CancerStatistics/FF/LifeLost.htm. Accessed Nov 30, 2009.

5. Motzer RJ, Bacik J, Murphy BA, Russo P, Mazumdar M. Interferon-alfa as a comparative treatment for clinical trials of new therapies against advanced renal cell carcinoma. J Clin Oncol. 2002;20:289-296.

6. Mekhail TM, Abou-Jawde RM, BouMerhi G, et al. Validation and extension of the Memorial Sloan-Kettering prognostic factors model for survival in patients with previously untreated metastatic renal cell carcinoma. J Clin Oncol. 2005;23:832-841.

7. Medical Council Renal Cancer Collaborators. Interferon- $\alpha$ and survival in metastatic renal carcinoma: early results of a randomized controlled trial. Lancet. 1999;353:14-17.

8. Figlin RA, Hutson TE, Tomczak P, et al. Overall survival with sunitinib versus interferon-alfa as first-line treatment of metastatic renal cell carcinoma. J Clin Oncol. 2008;26(suppl):abstr 5024. Abstract and associated presentation available from http://www.asco. org/ASCOv2/Meetings/Abstracts? \&vmview=abst_meeting_categories_view\&confID $=55$. Accessed Nov 30, 2009.

9. Coppin C, Porzsolt F, Autenreith M, Kumpf J, Coldman A, Wilt T. Immunotherapy for advanced renal cell cancer. Cochrane Database Syst Rev. 2004(3):CD001425, updated 18 May, 2006.

10. Coppin C, Le L, Porzsolt F, Wilt T. Targeted therapy for advanced renal cell cancer. Cochrane Database Syst Rev. 2008(2):CD006017.

11. Gleave ME, Elhilali M, Fradet $Y$, et al. Interferon gamma-1b compared with placebo in metastatic renal-cell carcinoma. $N$ Engl J Med. 1998;338:1265-1271.

12. Ravaud A, Hawkins R, Gardner J, et al. Lapatinib versus hormone therapy in patients with advanced renal cell carcinoma: a randomized phase III clinical trial. J Clin Oncol. 2008;26:2285-2291.

13. Fyfe G, Fisher RI, Rosenberg SA, Sznol M, Parkinson DR, Louie AC. Results of treatment of 255 patients with metastatic renal cell carcinoma who received high-dose recombinant interleukin-2 therapy. $J$ Clin Oncol. 1995;13:688-696.

14. Pyrhonen S, Salminen E, Ruutu M, et al. Prospective randomized trial of interferon alfa-2a plus vinblastine versus vinblastine alone in patients with advanced renal cell cancer. J Clin Oncol. 1999;17:2859-2867.

15. Rini BI, Cambell SC, Escudier B. Renal cell carcinoma. Lancet. 2009:373;1119-1132.

16. Rini BI. Metastatic renal cell carcinoma: many treatment options, one patient. J Clin Oncol. 2009;27:3225-3234.

17. Motzer RJ, Hutson TE, Tomczak P, et al. Overall survival and updated results for sunitinib compared with interferon alfa in patients with metastatic renal cell carcinoma. J Clin Oncol. 2009;27:3584-3590.

18. Escudier B, Eisen T, Stadler WM, et al. Sorafenib in advanced clear-cell renal-cell carcinoma. N Engl J Med. 2007;356:125-134.

19. Bracarda S, Patard J, Ravaud A. Current perspectives in metastatic renal cell carcinoma treatment: the role of mammalian target of rapamycin (mTOR) inhibition. Eur Urol Suppl. 2009;8:785-786. 
20. Hudes G, Carducci M, Tomczak P, et al. Temsirolimus, interferon alfa, or both for advanced renal-cell carcinoma. NEngl J Med. 2007;356:22712281.

21. Vezina C, Kudelski A, Sehgal SN. Rapamycin (AY-22,989), a new antifungal antibiotic. I. Taxonomy of the producing Streptomycete and isolation of the active principle. J Antibiot (Tokyo). 1975;28: 721-726.

22. Calne RY, Lim S, Samaan A, et al. Rapamycin for immunosuppression in organ allografting. Lancet. 1989;2:227.

23. Strimpakos AS, Karapanagiotou EM, Saif MW, Syrigos KN. The role of mTOR in the management of solid tumors: an overview. Cancer Treat Rev. 2009;35:148-159.

24. Harrison DE, Strong R, Sharp ZD, et al. Rapamycin fed late in life extends lifespan in genetically heterogeneous mice. Nature. 2009;460:392-396.

25. Huang S, Bjornsti M, Houghton PJ. Rapamycins. Mechanism of action and cellular resistence. Cancer Biol Ther. 2003;2:222-232.

26. Hudes GR. Targeting mTOR in renal cell carcinoma. Cancer. 2009;115(10 Suppl):2313-2320.

27. Hay N, Sonenberg N. Upstream and downstream of mTOR. Genes Dev. 2004;18:1926-1945.

28. Sabatini DM. mTOR and cancer: insights into a complex relationship. Nat Rev Cancer. 2006;6:729-734.

29. Abraham RT, Gibbons JJ. The mammalian target of rapamycin signaling pathway: twists and turns in the road to cancer therapy. Clin Cancer Res. 2007;13:3109-3114.

30. Hanna SC, Heathcote SA, Kim WY. mTOR pathway in renal cell carcinoma. Expert Rev Anticancer Ther. 2008;8:283-292.

31. Choi J, Chen J, Schreiber SL, Clardy J. Structure of the FKBP12rapamycin complex interacting with the binding domain of human FRAP. Science. 1996;273:239-242.

32. Lane HA, Wood JM, McSheehy PMJ, et al. mTOR inhibitor RAD001 (everolimus) has antiangiogenic/vascular properties distinct from a VEGFR tyrosine kinase inhibitor. Clin Cancer Res. 2009;15: $1612-1622$.

33. Manegold PC, Paringer C, Kulka U, et al. Antiangiogenic therapy with mammalian target of rapamycin inhibitor RAD001 (everolimus) increases radiosensitivity in solid cancer. Clin Cancer Res. 2008; $14: 892-900$.

34. Rini BI, Atkins MB. Resistance to targeted therapy in renal-cell carcinoma. Lancet Oncol. 2009;10:992-1000.

35. O'Reilly KE, Rojo F, She Q, et al. mTOR inhibition induces upstream receptor kinase signaling and activates Akt. Cancer Res. 2006;66: $1500-1508$.

36. Toschi A, Lee E, Gadir N, Ohh M, Foster DA. Differential dependence of hypoxia-inducible factors $1 \alpha$ and $2 \alpha$ on mTORC1 and mTORC2. J Biol Chem. 2008;283:34495-34499.

37. Harding MW. Immunophilins, mTOR, and pharmacodynamic strategies for a targeted cancer therapy. Clin Cancer Res. 2003;9: 2882-2886.

38. Boulay A, Zumstein-Mecker S, Stephan C, et al. Antitumor efficacy of intermittent treatment schedules with the rapamycin derivative RAD001 correlates with prolonged inactivation of ribosomal protein S6 kinase 1 in perpheral blood mononuclear cells. Cancer Res. 2004;64: $252-261$.

39. Tabernero J, Rojo F, Calvo E, et al. Dose- and schedule-dependent inhibition of the mammalian target of rapamycin pathway with everolimus: a phase I tumor pharmacodynamic study in patients with advanced solid tumors. J Clin Oncol. 2008;26:1603-1610.

40. O'Donnell A, Faivre S, Burris HA, et al. Phase I pharmacokinetic and pharmacodynamic study of the oral mammalian target of rapamycin inhibitor everolimus in patients with advanced solid tumors. $J$ Clin Oncol. 2008;26:1588-1595.

41. Tanaka C, O'Reilly T, Kovarik JM, et al. Identifying optimal biological doses of everolimus (RAD001) in patients with cancer based on the modeling of preclinical and clinical pharmacokinetic and pharmacodynamic data. J Clin Oncol. 2008;26:1596-1602.
42. Tabernero J, Rojo F, Burris H, et al. A phase I study with tumor molecular pharmacodynamic (MPD) evaluation of dose and schedule of the oral mTOR-inhibitor Everolimus (RAD001) in patients (pts) with advanced solid tumors. J Clin Oncol. 2005;23(suppl):abstr 3007.

43. Strom T, Haschke M, Zhang YL, et al. Identification of everolimus metabolite patterns in trough blood samples of kidney transplant patients. Ther Drug Monit. 2007;29:592-599.

44. European summary of product characteristics: Afinitor $10 \mathrm{mg}$. Novartis global. http://www.afinitor.com/global/docs/Afinitor-CD-EN-10 mg.pdf. Accessed Nov 30, 2009.

45. Amato RJ, Jac J, Giessinger S, Saxena S, Willis JP. A phase 2 study with a daily regimen of the oral mTOR inhibitor RAD001 (everolimus) in patients with metastatic clear cell renal cell cancer. Cancer. 2009;115:2438-2446.

46. Jac J, Amato RJ, Giessinger S, Saxena S, Willis JP. A phase II study with a daily regimen of the oral mTOR inhibitor RAD001 (everolimus) in patients with metastatic renal cell carcinoma which has progressed on tyrosine kinase inhibition therapy. J Clin Oncol. 2008;26(suppl);abstr 5113.

47. Motzer RJ, Escudier B, Oudard S, et al. Efficacy of everolimus in advanced renal cell carcinoma: a double-blind, randomised, placebocontrolled phase III trial. Lancet. 2008;372:449-456.

48. Kay A, Motzer R, Figlin R, et al. Updated data from a phase III randomized trial of everolimus (RAD001) versus PBO in metastatic renal cell carcinoma. American Society of Clinical Oncology Genitourinary Cancers Symposium. 2009; abstr 278. Abstract and associated presentation by RJ Motzer available from http://www.asco. org/ASCOv2/Meetings/Abstracts?\&vmview=abst_meeting_categories_ view\&confID=64. Accessed Nov 30, 2009.

49. Motzer RJ, Bacik J, Schwartz LH, et al. Prognostic factors for survival in previously treated patients with metastatic renal cell carcinoma. J Clin Oncol. 2004;22:454-463.

50. Therasse P, Arbuck SG, Eisenhauer EA, et al. New guidelines to evaluate the response to treatment in solid tumors. $J$ Natl Cancer Inst. 2000;92:205-216.

51. Knox JJ. Progression-free survival as endpoint in metastatic RCC? Lancet. 2008;372:427-429.

52. Delea T, Khuu A, Kay A, Zheng J, Baladi JF. Association between time to disease progression endpoints and overall survival in patients with metastatic renal cell carcinoma. Eur J Cancer. 2009;7(S2):abstr 7124.

53. Wiederkehr D, Howe CJ, Casciano R, Motzer R, Zheng J, Baladi JF. Overall survival among metastatic renal cell carcinoma patients corrected for crossover using inverse probability of censoring weights: analysis from the RECORD-1 phase 3 trial. Eur J Cancer. 2009;7(S2): abstr 7131 .

54. Korhonen P, Haas T, Zuber E, Kay A, Lebwohl D, Motzer R. Overall survival among metastatic renal cell carcinoma patients corrected for crossover using a rank preserving structural failure time model: analysis from the everolimus phase 3 trial. Eur J Cancer. 2009;7(S2): abstr 7155 .

55. Common terminology criteria for adverse events v3.0. Cancer Therapy Evaluation Program, US National Cancer Institute. 2006. http:// ctep.cancer.gov/protocolDevelopment/electronic_applications/ctc. htm\#ctc_30. Accessed Nov 30, 2009.

56. Chhajed PN, Dickenmann M, Bubendorf L, Mayr M, Steiger J, Tamm M. Patterns of pulmonary complications associated with sirolimus. Respiration. 2006;73:367-374.

57. Pablo M, Hudes G, Dutcher J, et al. Radiographic findings of druginduced pneumonitis and clinical correlation in patients with advanced renal cell carcinoma treated with temsirolimus. Eur J Cancer. 2009;7(S2):abstr 7113.

58. Albiges $\mathrm{L}$, Caramella $\mathrm{C}$, Ferte $\mathrm{C}$, et al. Interstitial pneumonitis during RAD001 treatment: incidence by blinded radiological analysis. Eur $J$ Cancer. 2009;7(S2):abstr 7114.

59. Motzer RJ, Escudier B, Oudard S, et al. RAD001 vs placebo in patients with metastatic renal cell carcinoma after progression on VEGFr-TKI therapy: results from a randomized, double-blind, multicenter phase-III study. J Clin Oncol. 2008;26(suppl):abstr LBA5026. 
60. Grunwald V, Rha SY, Miller K, et al. An international expanded access program of RAD001(everolimus) in patients with metastatic renal cell carcinoma who fail or become intolerant of a prior vascular endothelial growth factor therapy. Eur J Cancer. 2009;7(S2):abstr 7154.

61. Expanded access study of RAD001 in metastatic renal cell cancer patients who are intolerant of or who have failed despite prior vascular endothelial growth factor therapy. NCT00655252. www.clinicaltrials. gov/ct2/results?term=NCT00655252. Accessed Nov 30, 2009.

62. Hutson TE, Davis ID, Machiels J-PH, et al. Efficacy and safety of pazopanib in patients with metastatic renal cell carcinoma. J Clin Oncol. 2010;28:475-480.

63. Rini BI, Wilding G, Hudes G, et al. Phase II study of axitinib in sorafenib-refractory metastatic renal cell carcinoma. J Clin Oncol. 2009;27:4462-4468.

64. Hutson TE, Figlin RA, Kuhn JG, Motzer RJ. Targeted therapies for metastatic renal cell carcinoma: an overview of toxicity and dosing strategies. Oncologist. 2008;13:1084-1096.

65. Bellmunt J, Szczylik C, Feingold J, Strahs A, Berkenblit A. Temsirolimus safety profile and management of toxic effects in patients with advanced renal cell carcinoma and poor prognostic features. Ann Oncol. 2008; 19:1387-1392.

66. Seruga B, Gan HK, Knox JJ. Managing toxicities and optimal dosing of targeted drugs in advanced kidney cancer. Curr Oncol. 2009;16(S1) S52-S59.

67. Atkins MB, Hidalgo M, Stadler WM, et al. Randomized phase II study of multiple dose levels of CCI-779, a novel mammalian target of rapamycin kinase inhibitor, in patients with advanced refractory renal cell carcinoma. J Clin Oncol. 2004;22:909-918.

68. Pendergrass KB, Hudes G, Radulovic S, et al. Characterization of hyperglycemia, hypercholesterolemia and hyperlipidemia in patients with advanced renal cell carcinoma treated with temsirolimus or interferon- $\alpha$. ASCO Genitourinary Cancers Symposium 2009; abstr 297. Abstract and slides available from http://www.asco.org/ASCOv2/Meetings/Abstracts?\&vmview=abst_meeting_categories_view\&confID=64. Accessed Nov 30, 2009.

69. Dutcher JP, de Souza P, McDermott D, Figlin RA, et al. Effect of temsirolimus versus interferon- $\alpha$ on outcome of patients with advanced renal cell carcinoma of different tumor histologies. Med Oncol. 2009;26:202-209.

70. Caglio S, Sundlov A, Slimane K, May C, Escudier B. Open-label phase II trial of everolimus monotherapy for patients with advanced papillary renal cell cancer (RAPTOR): rationale and design. Eu J Cancer. 2009;7(S2):abstr 7156.

71. RAPTOR: RAD001 as monotherapy in the treatment of advanced papillary renal cell tumors program in Europe (RAPTOR/LFR08). NCT00688753. Available from http://www.clinicaltrials.gov/ct2/ results?term=NCT00688753. Accessed Nov 30, 2009.

72. RAD001 (everolimus) for advanced renal cell carcinoma before kidney removal. NCT00831480. http://www.clinicaltrials.gov/ct2/results?term= NCT00831480. Accessed Nov 30, 2009.

73. Pantuck AJ, Seligson DB, Klatte T, et al. Prognostic relevance of the mTOR pathway in renal cell carcinoma. Cancer. 2007;109:2257-2267.

74. Cho D, Signoretti D, Dabora S, et al. Potential histologic and molecular predictors of response to temsirolimus in patients with advanced renal cell carcinoma. Clin Genitourin Cancer. 2007;5:379-385.

Biologics: Targets \& Therapy

\section{Publish your work in this journal}

Biologics: Targets \& Therapy is an international, peer-reviewed journal focusing on the patho-physiological rationale for and clinical application of Biologic agents in the management of autoimmune diseases, cancers or other pathologies where a molecular target can be identified This journal is indexed on PubMed Central, CAS, EMBase, Scopus
75. Figlin RA, de Souza P, McDermott D, et al. Analysis of PTEN and HIF- $1 \alpha$ and correlation with efficacy in patients with advanced renal cell carcinoma treated with temsirolimus versus interferon- $\alpha$. Cancer. 2009; 115:3651-3660.

76. Biomarker trial of everolimus in patients with advanced renal cell carcinoma. NCT00827359. http://www.clinicaltrials.gov/ct2/results?t erm=NCT00827359. Accessed Nov 30, 2009.

77. Nogova L, Zander T, Gross SH, et al. Pharmacodynamics of RAD001 measured by early FDG PET in patients with recurrent NSCLC. J Clin Oncol. 2008;26(suppl):abstr 14616.

78. Sosman J, Puzanov I. Combination targeted therapy in advanced renal cell carcinoma. Cancer. 2009;115(10 suppl):2368-2375.

79. Ryan CW, Vuky J, Chan JS, Beer TM, Rothkopf M. Phase II study of everolimus with imatinib in patients with previously-treated renal carcinoma. J Clin Oncol. 2009;27(suppl):abstr e16075.

80. Kroog GS, Feldman DR, Kondagunta GV, et al. Phase I trial of RAD001 (everolimus) plus sunitinib in patients with metastatic renal cell carcinoma. J Clin Oncol. 2009;27(suppl):abstr 5037.

81. Harzstark AL, Rosenberg JE, Weinberg VK, et al. A phase I study of sorafenib and RAD001 for metastatic clear cell renal cell carcinoma. J Clin Oncol. 2009:27(suppl):abstr 5104.

82. ZafarY, Bendell J, Lager J, et al. Preliminary results of a phase I study of bevacizumab in combination with everolimus in patients with advanced solid tumors. J Clin Oncol. 2006;24(suppl):abstr 3097.

83. Whorf RC, Hainsworth JD, Spigel DR, et al. Phase II study of bevacizumab and everolimus (RAD001) in the treatment of advanced renal cell carcinoma. J Clin Oncol. 2008;26(suppl):abstr 5010. Abstract and associated presentation by JD Hainsworth available from http:// www.asco.org/ASCOv2/Meetings/Abstracts?\&vmview=abst_meeting categories_view\&confID $=55$. Accessed Nov 30, 2009.

84. Safety and efficacy of bevacizumab plus RAD001 versus interferon alfa-2a and bevacizumab in adult patients with kidney cancer (L2201). NCT00719264. http:/www.clinicaltrials.gov/ct2/results?term=NCT00 719264. Accessed Nov 30, 2009.

85. Efficacy and safety comparison of RAD001 versus sunitinib in the first-line and second-line treatment of patients with metastatic renal cell carcinoma (RECORD3). NCT00903175. http://www.clinicaltrials. gov/ct2/results?term=NCT00903175. Accessed Nov 30, 2009.

86. Soulieres D. Review of guidelines on the treatment of metastatic renal cell carcinoma. Curr Oncol. 2009;16(S1):S67-S70.

87. Kidney cancer treatment for advanced disease, predominant clear cell histology, subsequent therapy after tyrosine kinase inhibitor therapy. National Comprehensive Cancer Network. Clinical Practice Guidelines in Oncology. Kidney Cancer. V.2.2010. http://www.nccn. org/professionals/physician_gls/f_guidelines.asp. Accessed Nov 30, 2009.

88. Escudier B, Kataja V. Renal cell carcinoma: ESMO clinical recommendations for diagnosis, treatment and follow-up. Ann Oncol. 2009;20(S4):iv81-iv82.

89. Canadian Kidney Cancer Forum 2009. Management of kidney cancer: Canadian Kidney Cancer Forum consensus update. Can Urol Assoc J. 2009;3:200-204.

\section{Dovepress}

and the Elsevier Bibliographic databases. The manuscript management system is completely online and includes a very quick and fair peerreview system, which is all easy to use. Visit http://www.dovepress. com/testimonials.php to read real quotes from published authors. 